\title{
Modified Palliation in Cancer Patients during COVID-19 Pandemic
}

\author{
Bhawna Wagle, Eliza Koirala
}

Department of Anesthesiology, B.P Koirala Memorial Cancer Hospital, Bharatpur, Nepal

\begin{abstract}
Coronavirus disease 2019 (COVID 19) has put huge challenge to the health delivery system all across the globe. The risk of mortality due to COVID 19 is highest on critically ill patients and those with preexisting disease. Palliative and end of life care are no exceptions to the surge in increased demand for health care services. It is now an essential part of global health care. The benefits of early palliative care are already well established. In the pandemic like this, we must not pull back the services, particularly in these vulnerable groups. It is important to determine how best to deliver palliative care during this crisis. It may include preparedness to shift the focus of resources to community level and the innovative use of telemedicine. Use of telemedicine is to ease patients and minimize caregiver distress, and to prevent hospitalizations. The fear of contracting COVID-19 and the emotional burden during diagnosis requires the need of continuous psychosocial support. These challenges should be handled by specialized and skilled interdisciplinary palliative care team.
\end{abstract}

Keywords: Cancer, COVID-19, Palliative Care.

\section{Background}

Coronavirus disease 2019 (COVID-19), caused by severe acute respiratory syndrome coronavirus (SARSCoV-2), was known to cause viral pneumonia in several patients, epidemiologically linked to a seafood market in Wuhan, Hubei province, China. ${ }^{1,2}$ Since then, the spread of COVID-19 started involving countries outside China, leading the World Health Organization (WHO) to characterize COVID-19 as the pandemic. ${ }^{3}$ COVID-19 pandemic is rapidly increasing across the world. The common symptoms include breathlessness, cough, myalgia, and fever.

The key attributes of palliative care and prerequisite components in response to epidemics and pandemics are the relief of suffering, supporting complex decision making, and managing clinical unpredictability. ${ }^{4}$ COVID-19 pandemic lead to a surge in demand for health care services, including palliative and end-oflife care. ${ }^{5}$ Palliative care is considered as a vital part of universal health coverage. The patients with active cancer are particularly susceptible to COVID-19, enforcing palliative care health care professionals to better define their identity. ${ }^{6}$

\section{Situation Address:}

The benefits of early palliative care have been well established over the last decades. Every patient with advanced cancer visits palliative care team within 8 weeks of diagnosis, as suggested by the American Society of Clinical Oncology. ${ }^{7}$ This leads to referral to palliative care as early as diagnosis, and growth in outpatient palliative care services. ${ }^{8}$ Palliative care professionals are facing dilemmas related to the added risk of exposure, new needs, and demands during the time of this pandemic. At the time of crisis like these, we must not pull back by decreasing services, rather we can still provide care in creative ways that remain consistent with the core of how we practice outside these unique circumstances. Facing challenges during this pandemic can be categorized, considering three types of population: outpatients, COVID-19 positive in-patients, and COVID-19 negative inpatients. New update by US Drug Enforcement Administration regulations

\section{Correspondence}

Dr. Bhawna Wagle, Consultant, Department of Anesthesiology, B.P Koirala Memorial Cancer Hospital, Bharatpur, Nepal, email: bit2wagle@yahoo.com 
allow palliative care professionals to continue opioid prescriptions using telemedicine. Both audio and video assessments are needed for new patients, whereas video assessments are not necessary for outpatients.

The use of telemedicine is to ease patient and caregiver distress and to prevent hospitalizations. Video visits allow us to see patients' home environment-information that is unavailable in traditional clinic visits. In an ambulatory setting, telemedicine can be an integral strategy to provide early palliation. However, it can be difficult to rapidly establish trust with new patients. Validation of emotions, response to questions, and use of communication tools should be implemented for virtual visits. Patients may be more willing to have these conversations with someone, other than their oncologist. ${ }^{9}$ Due to limited personal protective equipment and restriction of family/caregiver visits, telemedicine is creatively used by palliative care practitioners in the inpatient setting for patients with and without COVID-19. Video visits can be a challenge to address two barriers. The first one is that they provide a form of face-to-face communication and the second is that they allow multiple health care professionals to engage patients/families/caregivers simultaneously.

Table 1: Possible modified patient approach ${ }^{6}$

\begin{tabular}{|c|c|}
\hline Type of patient & Modified patient approach \\
\hline Outpatient & $\begin{array}{l}\text { - Opioid prescription via telemedicine } \\
\text { - Prevent hospitalization by educating } \\
\text { caregivers } \\
\text { - Limit hospice referrals to limit } \\
\text { exhaustion of the resource } \\
\text { - Maintain physical distance with video } \\
\text { call and phone calls }\end{array}$ \\
\hline $\begin{array}{l}\text { Inpatient } \\
\text { COVID-19 } \\
\text { positive }\end{array}$ & $\begin{array}{l}\text { - Mindful use of manpower and } \\
\text { Personal protective equipment } \\
\text { - Symptom specific management guidance } \\
\text { - Limit medication frequency } \\
\text { - Psychosocial support for overcoming } \\
\text { fear and grief } \\
\text { - Safe discharge as early as possible }\end{array}$ \\
\hline $\begin{array}{l}\text { Inpatient } \\
\text { COVID-19 } \\
\text { negative }\end{array}$ & 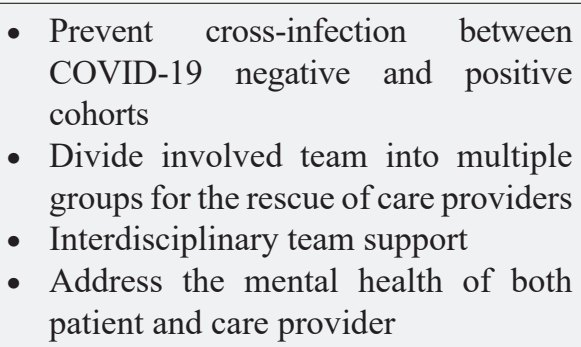 \\
\hline
\end{tabular}

With limited medical resources and the requirement of prolonged isolation during the time of the COVID-19 pandemic, patients still require advanced care. Palliative care professionals can still give a significant amount of time to provide patients/families with emotional support, using therapeutic presence and touch but it needs to be efficient to have a similar influence while limiting physical contact. As telehealth is time-consuming; health care professionals may lack availability and time. The fear of contracting COVID-19 and the emotional burden during diagnosis requires the need for psychosocial support. The development of guilt and post-traumatic stress disorder may develop during survivability. These challenges should be handled by specialized and skilled interdisciplinary palliative care team. Additionally, the management of complex symptoms, including dyspnea, anorexia, and delirium, has to be done efficiently.

\section{Conclusion}

Palliative care is a necessity, not a luxury during the time of this pandemic. We have to be cognizant of our patients' and our safety and continue to provide palliative care services at this crucial time. Palliative care providers need to innovate creative techniques in the time of ventilator shortages and difficult choices. As a result, it can consolidate and establish our identity in this field.

\section{References}

1. Zhu N, Zhang D, Wang W, Li X, Yang B, Song J, Zhao X, Huang B, Shi W, Lu R, Niu P. A novel coronavirus from patients with pneumonia in China, 2019. New England Journal of Medicine. 2020 Jan 24.

2. Lu R, Zhao X, Li J, Niu P, Yang B, Wu H, Wang W, Song H, Huang B, Zhu N, Bi Y. Genomic characterization and epidemiology of 2019 novel coronavirus: implications for virus origins and receptor binding. The Lancet. 2020 Feb 22; 395 (10224):565-74.

3. World Health Organization. WHO DirectorGeneral's opening remarks at the media briefing on COVID-19-11 March 2020.

4. Powell RA, Schwartz L, Nouvet E, Sutton B, Petrova M, Marston J, Munday D, Radbruch L. Palliative care in humanitarian crises: always something to offer.

5. Downar J, Seccareccia D, Associated Medical Services Inc. Educational Fellows in Care at the End of Life. Palliating a pandemic: "all patients must be cared for". Journal of Pain and symptom management. 2010 Feb 1; 39(2):291-5. 
6. Rate CF. Characteristics of Patients Dying in Relation to COVID-19 in Italy Onder G, Rezza G, Brusaferro S. JAMA. Published online March. 2020; 23.

7. Temel J, Greer J, Pirl W. Early Palliative Care in NonSmall-Cell Lung Cancer. The New England Journal of Medicine. 2010 Dec 2; 363(23):2264-5.

8. Meier DE, Back AL, Berman A, Block SD, Corrigan JM, Morrison RS. A national strategy for palliative care. Health affairs. 2017 Jul 1;36 (7):1265-73.

9. Dow LA, Matsuyama RK, Ramakrishnan V, Kuhn L, Lamont EB, Lyckholm L, Smith TJ. Paradoxes in advance care planning: the complex relationship of oncology patients, their physicians, and advance medical directives. Journal of Clinical Oncology. 2010 Jan 10;28 (2):299. 